\title{
Influence of Calibration Parameter Selection on Flash Flood Simulation for Small to Medium Catchments with MISDc-2L Model
}

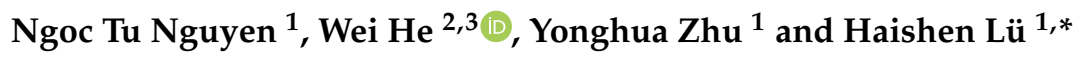 \\ 1 State Key Laboratory of Hydrology-Water Resources and Hydraulic Engineering, College of Hydrology and \\ Water Resources, Hohai University, Nanjing 210098, China; ngoctu.nguyen.vn@gmail.com (N.T.N.); \\ zhuyonghua@hhu.edu.cn (Y.Z.) \\ 2 International Institute for Earth System Science, Nanjing University, Nanjing 210023, China; \\ weihe@nju.edu.cn \\ 3 Jiangsu Provincial Key Laboratory of Geographic Information Science and Technology, Key Laboratory for \\ Land Satellite Remote Sensing Applications of Ministry of Natural Resources, School of Geography and \\ Ocean Science, Nanjing University, Nanjing 210023, China \\ * Correspondence: haishenlu@gmail.com; Tel.: +86-25-8378-6891
}

Received: 24 October 2020; Accepted: 18 November 2020; Published: 20 November 2020

\begin{abstract}
It is of great challenge to accurately predict flash floods for small to medium catchments (SMC) in mountainous areas, for which parameter calibration strategies are crucial for model performance. This study investigates the influence of calibration parameter selection on flash flood simulations using a rainfall-runoff model, MISDc-2L (Modello Idrologico Semi-Distribuito in continuo-2 layers), at hourly scale for SMC in the Huai River basin of China over the 2010-2015 period. We investigated model performances under different calibration schemes, where different amounts of model parameters were selected for the calibration procedure. The model clearly performed better in the case involving calibration of partial sensitive parameters than that of a full parameter set with respect to the peaks, the hydrographs and the base-flow of flood simulation, especially after including maximum water capacity (W_max) in the calibration. This finding was consistently valid under different model calibration experiments, including single event, "split-sample" test and combined events at different flood magnitude levels. We further found that the model performed better for high magnitude flood events than medium and low ones, but clear improvements can be achieved for low and medium magnitude flood events with careful calibration parameter selection. Our study suggests that calibration parameter selection is important for flash flood event simulations with the MISDc-2L model for SMC in the Huai River basin of China; specifically, the reduction in calibration parameter amount and the inclusion of W_max in calibration remarkably improve flood simulation.
\end{abstract}

Keywords: MISDc-2L model; flash flood simulation; calibration parameter selection; maximum water capacity; small to medium catchment; Huai River basin

\section{Introduction}

In recent decades, flash floods have become one of the most severe natural hazards in the context of global climate change [1,2]. Flash floods threaten human lives and properties worldwide with potentially devastating consequences, giving rise to one third of all losses due to natural disasters [2-5]. Unfortunately, with increasing intense precipitation over highly saturated soils in mountainous terrain, flash flooding events are likely to be more frequent over the globe [6]. However, the forecasting and warning of flash floods of small-scale catchments in mountainous areas faces various challenges, 
which urgently calls for the development of effective models and calibration methods for predicting flash floods [7].

Over past decades, numerous hydrological models with simple to complex structures were developed as a useful tool to deal with flood simulation [8]. Hydrological models are classified as lumped models and distributed models [9]. Distributed models consider the spatial distribution of land surface features, e.g., the Digital Elevation Model (DEM) and land cover type, however, it has a complex structure and requires intensive computation. Lumped models have a simple structure and require low computation, which proves that they effectively simulate flood events in small catchments $\left(<2000 \mathrm{~km}^{2}\right)$ [9-11]. Complex models do not always perform better than simple ones [8,9,11-14]. Boithias et al. [12] reported that the lumped SWAT model and distributed MARINE model equally satisfactorily simulated flood events, and Li et al. [13] found that the distributed SWAT model and lumped XAJ (Xin'anjiang) model performed sub-daily simulation fairly in small catchments. Similarly, Huang et al. [14] reported that the distributed HBV model does not outperform the lumped HBV model. These authors stated that increasing spatiality in the model structure is not the main reason to improve model performances but the rainfall quality and quantity are the most important factors influencing the simulation result $[11,14]$.

To date, only a few models have been designed to simulate flash flood events, because it is difficult to accurately describe runoff processes of flash events due to their short duration, fast recession and the peak of discharge being sustained only for a few hours or a few minutes [15-17]. A couple of studies have extended daily models to simulate floods at sub-daily and hourly time steps using existing rainfall-runoff models, e.g., SWAT $[12,13,18,19]$. In contrast, the MISDc-2L model was designed to simulate flood events at hourly time steps. It combines a soil water balance (SWB) model and a semi-distributed event-based rainfall-runoff model (MISD) with a two-layer scheme for better representation of the soil moisture state [20]. The MISDc-2L model is advantageous due to its simple structure and low data requirements, and has been proven to effectively simulate flash floods at small catchments in Italy, America and other European countries [20-26]. Nonetheless, the performance of flood simulation varies with different environmental conditions, especially for mountainous areas [5,21]. Thus, it is necessary to examine the MISDc-2L capacity in different regions like China.

Although the MISDc-2L model has been applied in several study areas in the world, its parametric uncertainties and its performances over other regions have not been analyzed. Previous works on the calibration of MISDc-2L often operated with the full parameter set, which could have led to the uncertainties in simulation. The uncertainty occurs where the values of the calibrated parameters do not realistically reflect watershed characteristics or the equifinality of parameter sets endures due to the value assignments of model parameters with multiple combinations $[27,28]$. The reduction in the calibration parameter amount along with sensitivity analysis is known as a useful method to lessen the computational consumption and uncertainties [29-31]. Gan et al. [31] reported that reducing the number of parameters of the CREST (Coupled Routing and Excess Storage) model from 12 to 7 based on sensitivity analysis improves the streamflow simulation. Moreover, several studies raised concerns about sensitive characteristic of parameters, whereby sensitive parameters should be calibrated while the insensitive parameter can be empirically set as a fixed value [32,33]. As one of the most sensitive parameters, W_max dominates the infiltration process for small to medium catchments, which controls the runoff generation in flood models [34]. However, W_max was set as a constant in previous studies using the MISDc-2L model, according to the spatial distribution of the Curve Number values computed from soil/land use characteristics and scaling factor based on the assumption about its variety in space [21]. This value is empirically determined from flood events for the catchments in limited study areas, but it may be inappropriate in other areas or catchments [35]. Hence, it is needed to assess the impact of W_max calibration on flood simulation.

This study aims to investigate the influence of calibration parameter selection on flash flood simulation for small to medium catchments with the MISDc-2L model in the Huai River basin of China. We focus on three main research questions: (1) How effective is the MISDc-2L model for flash 
flood simulations at hourly time-steps in the Huai River basin of China? (2) Is the reducing of the amount of calibration parameters favorable for streamflow simulation? (3) Does the inclusion of parameter maximum water capacity on calibration lead to the improvement in flood simulations with the MISDc-2L model? To address these questions, the paper is organized as follows: Sections 2 and 3 describe the study area, data and methodology including model structure and model constraining strategies, Section 4 presents the results about model applicability with different calibration schemes, and Section 5 includes the discussion and Section 6 provides conclusions.

\section{Study Area}

The study area, namely the Huangnizhuang catchment $\left(31^{\circ} 06^{\prime}-31^{\circ} 42^{\prime} \mathrm{N}, 115^{\circ} 21^{\prime}-115^{\circ} 43^{\prime} \mathrm{E}\right.$, $805 \mathrm{~km}^{2}$ ) is located in the upstream section of Shiguan River, which is the first tributary of the Huai River Basin, Anhui Province, China (Figure 1).

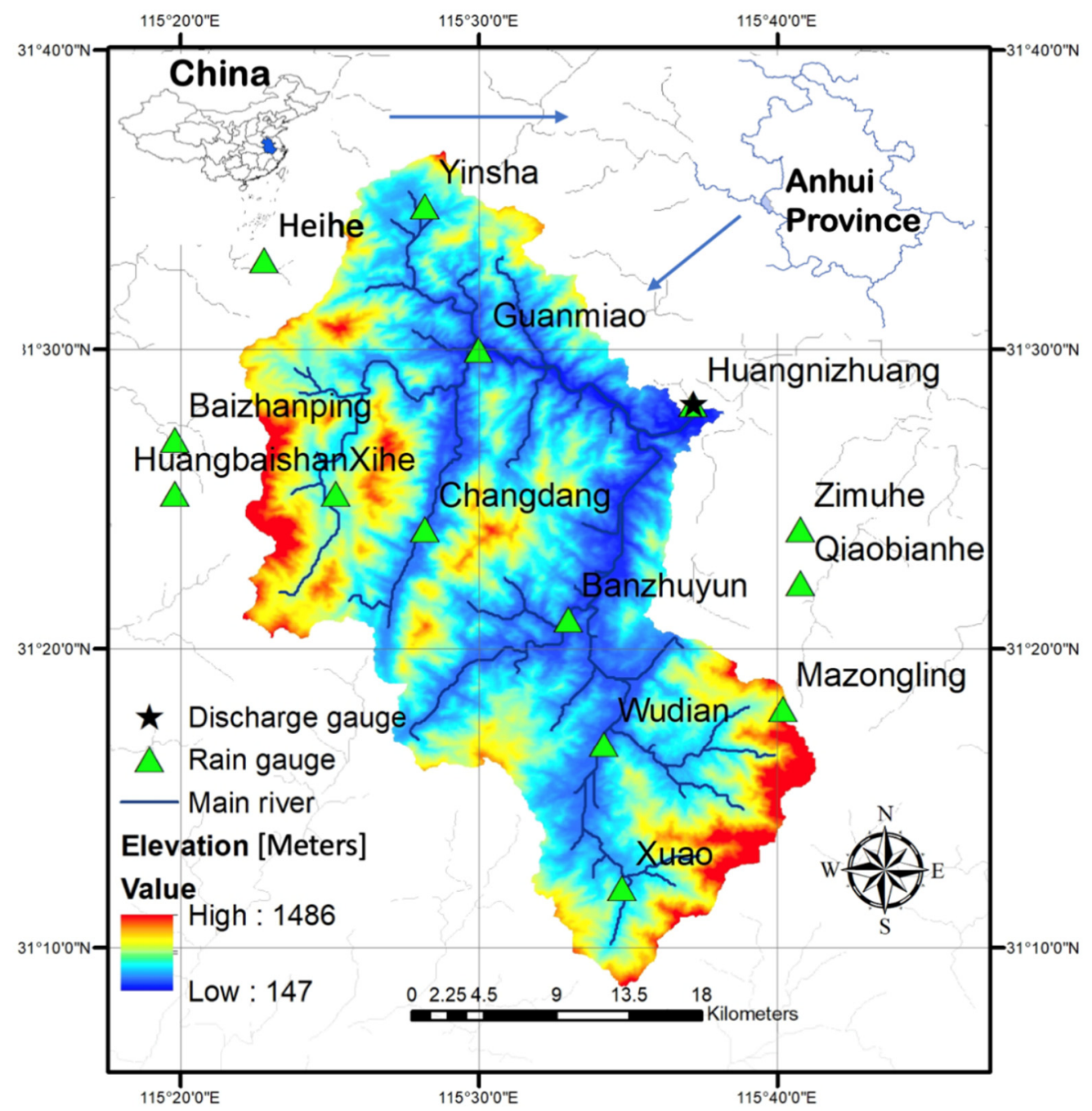

Figure 1. Morphology of the upstream Shiguan River with the location of the hydrometeorological monitoring network.

The upstream Shiguan River is a deep mountain area with deep valleys and steep slopes. The surrounding underlying surface is well covered by vegetation and is rich with granite and gneiss. The Huangnizhuang catchment has a loose sand bed structure and strong water permeability. It contains a complex topographical setting, including highly mountainous, hilly areas with a maximum elevation of $1495 \mathrm{~m}$ where the streamflow is very rapid, and a low alluvial plain where the drainage network is well developed. It has different land cover properties; woodland accounts for $81.01 \%$ of the 
total catchment, wooded grassland covers $9.21 \%$, temperate deciduous forest (3.92\%), mixed-forest $(2.83 \%)$, and cropland and evergreen forest (3.01\%). It has a monsoonal climate, which is affected by the climate of the Huai River and $60-70 \%$ of the annual precipitation is concentrated in summer. The mean annual air temperature is $11-16^{\circ} \mathrm{C}$ and the mean annual precipitation is around $1077 \mathrm{~mm}$. The precipitation in the rainy season from June to September accounts for almost 50-80\% of annual total and greatly varies from year to year. This area is a center of rainstorm. Favorable geographical and climate characteristics, combined with heavy rain, commonly occur during drought seasons, causing flash floods in the study area.

\section{Data and Methods}

\subsection{Data Collection}

\subsubsection{Discharge Data}

Hourly discharge observations were collected from the Annual Hydrological Report produced by the Bureau of Hydrology, Ministry of Water Resources, P. R. China, from 2010 to 2015. A total of 15 flood events were selected for this study and their main characteristics, e.g., duration, magnitude of floods, peak of discharge and maximum rainfall, are summarized in Table 1.

Table 1. Characteristics of the selected rainfall-runoff events for this study.

\begin{tabular}{ccccccc}
\hline $\begin{array}{c}\text { Event } \\
\text { No. }\end{array}$ & $\begin{array}{c}\text { Single-Event } \\
\text { ID }\end{array}$ & $\begin{array}{c}\text { Date of } \\
\text { Flood Start }\end{array}$ & $\begin{array}{c}\text { Dates of } \\
\text { Flood End }\end{array}$ & $\begin{array}{c}\text { Peak Discharge } \\
\left(\mathbf{m}^{\mathbf{3}} / \mathbf{s}\right)\end{array}$ & $\begin{array}{c}\text { Maximum } \\
\text { Rainfall }(\mathbf{m m})\end{array}$ & $\begin{array}{c}\text { Magnitude Level of } \\
\text { Flood Events }\end{array}$ \\
\hline 1 & 20100608 & $08 / 06 / 2010$ & $14 / 06 / 2010$ & 216 & 22.4 & Low \\
2 & 20100611 & $11 / 07 / 2010$ & $15 / 07 / 2010$ & 944.06 & 37.1 & High \\
3 & 20100719 & $19 / 07 / 2010$ & $27 / 07 / 2010$ & 405 & 36.3 & Medium \\
4 & 20100902 & $02 / 09 / 2010$ & $09 / 09 / 2010$ & 220 & 69 & Low \\
5 & 20110618 & $18 / 06 / 2011$ & $21 / 06 / 2011$ & 1040 & 29 & High \\
6 & 20110624 & $24 / 06 / 2011$ & $28 / 06 / 2011$ & 467.8 & 49.5 & Medium \\
7 & 20110810 & $10 / 08 / 2011$ & $13 / 08 / 2011$ & 210 & 34 & Low \\
8 & 20120613 & $13 / 07 / 2012$ & $17 / 07 / 2012$ & 966.44 & 44.5 & High \\
9 & 20120809 & $09 / 08 / 2012$ & $15 / 08 / 2012$ & 275.02 & 18 & Medium \\
10 & 20130624 & $24 / 06 / 2013$ & $28 / 06 / 2013$ & 261.53 & 33.5 & Medium \\
11 & 20130706 & $06 / 07 / 2013$ & $10 / 07 / 2013$ & 1628.5 & 47.5 & High \\
12 & 20140704 & $04 / 07 / 2014$ & $07 / 07 / 2014$ & 734 & 34 & High \\
13 & 20140831 & $31 / 08 / 2014$ & $05 / 09 / 2014$ & 281.7 & 26 & Medium \\
14 & 20150626 & $26 / 06 / 2015$ & $03 / 07 / 2015$ & 239.1 & 20 & Low \\
15 & 20150809 & $09 / 08 / 2015$ & $14 / 08 / 2015$ & 560 & 53 & High \\
\hline
\end{tabular}

The flood events were classified by different magnitude levels, namely low-magnitude flood, medium-magnitude flood and high-magnitude flood (Table 1). High-magnitude floods are defined as having a maximum discharge greater than $500 \mathrm{~m}^{3} / \mathrm{s}$, medium-magnitude floods are defined by a maximum discharge from $250 \mathrm{~m}^{3} / \mathrm{s}$ to less than $500 \mathrm{~m}^{3} / \mathrm{s}$, and low-magnitude floods are defined by a maximum discharge of less than $250 \mathrm{~m}^{3} / \mathrm{s}$. The flood events were selected where each class of flood magnitude levels had same pre-condition. The high-magnitude events were followed by the medium-magnitude events, and the medium-magnitude ones were followed by low-magnitude ones.

\subsubsection{Meteorological Data}

The meteorological data required to force the MISD-2L model include precipitation and air temperature in hourly time steps. Hourly ground-based rainfall data were collected for 14 rain-gauge stations, with 8 stations situated inside of the catchment and 6 stations outside of the catchment (Table 2, shown in Figure 1) from the Annual Hydrological Report. According to the number of stations, the representative rainfall at the catchment was calculated from the rainfall gauge station data by the inverse distance weighted (IDW) method with Python. Hourly air temperature data were collected from the China Meteorological Administration (CMA) land data assimilation system (CLDAS) version 2.0, 
provided by the China Meteorological Data Service Center, which is available at http://data.cma.cn/. The National Meteorological Information Center (NMIC) of the CMA developed the CLDAS by data fusion and assimilation technology. In this study, we used the CLDAS air temperature data at hourly temporal steps from 2010 to 2015. The air temperature for each event was generated by the IDW interpolation method.

Table 2. Meteorological gauge stations at the upstream Shiguan River catchment.

\begin{tabular}{cccc}
\hline Station ID & Station Name & Longitude (Degree) & Latitude (Degree) \\
\hline 1 & Chandang & 115.47 & 31.4 \\
2 & Xihe & 115.42 & 31.42 \\
3 & Guanmiao & 115.5 & 31.5 \\
4 & Yinsha & 115.47 & 31.58 \\
5 & Xuao & 115.58 & 31.2 \\
6 & Wudian & 115.57 & 31.28 \\
7 & Banzhuyun & 115.55 & 31.35 \\
8 & Huangnizhuang & 115.62 & 31.47 \\
9 & Mazongling & 115.67 & 31.3 \\
10 & Qiaobianhe & 115.68 & 31.37 \\
11 & Zimuhe & 115.68 & 31.4 \\
12 & Huangbaishan & 115.33 & 31.42 \\
13 & Baizhanping & 115.33 & 31.45 \\
14 & Heihe & 115.38 & 31.55 \\
\hline
\end{tabular}

\subsection{MISDc-2L Model}

The MISDc-2L (Modello Idrologico Semi-Distribuito in continuo-2 layers) model was developed from the one-layer MISDc model and the soil is subdivided into two zones, namely, the surface and root zones [20,21]. Basically, there is no difference in model structure between the two versions, where the model couples two components: a soil water balance (SWB) model and a semi-distributed event-based rainfall-runoff model (MISD). In the context of the SWB model, the temporal evolution of soil water includes two independent states, $W_{1}$ and $W_{2}$, by which the water is extracted from the first layer by evapotranspiration, which is calculated by a linear function between the potential evaporation, estimated via the Blaney and Criddle relation modified by Doorenbos and Pruitt [36], and the soil saturation. Subsequently, the percolation from the surface to the root zone layer is calculated via a non-linear relation proposed by Famiglietti and Wood [37]. The reader is referred to Brocca et al. [38] for a full description of the formula using in the SWB model. The MISD model is an event-based rainfall-runoff model developed by Corradini et al. [39], which was spatially set-up in a lumped way as described in following process: (1) the rainfall excess is calculated by the Soil Conservation Service (SCS-CN) formula, which is used as a function of the first layer soil saturation; (2) base-flow is a non-linear function of the soil moisture content of the third layer [40]. The runoff was generated from different sources, such as the surface runoff, the saturation excess from the surface, the deep layer and the sub-surface runoff component. The first two sources are calculated via estimation of the losses and the Geo-morphological Instantaneous Unit Hydro-graph (GIUH), while the subsurface runoff is calculated by a linear reservoir approach in the catchment and in the area draining directly into the main channel. The lag time is estimated via the relationship proposed by Corradini et al. [41]. A detailed description of the modeling concept and the equations applied for each element in catchment can be found in $[20,21,38]$. The parameters of the MISDc-2L model and their ranges are listed in Table 3. 
Table 3. Parameters of the MISDc-2L model.

\begin{tabular}{cccc}
\hline Parameter & Description & Unit & Range of Variability \\
\hline W_max & Maximum water capacity of the 1st layer & $\mathrm{mm}$ & $50-700$ \\
W_max2 & Maximum water capacity of the 2nd layer & $\mathrm{mm}$ & $300-4000$ \\
W_p & Initial condition & $/$ & $0-1$ \\
$\mathrm{~m}$ & Exponent of drainage for the 1st layer & $/$ & $2-10$ \\
$\mathrm{~m} 2$ & Exponent of drainage for the 2nd layer & $/$ & $5-20$ \\
$\mathrm{Ks}$ & Hydraulic conductivity of the 1st layer & mm/day & $0.1-20.0$ \\
$\mathrm{Ks} 2$ & Hydraulic conductivity of the 2nd layer & mm/day & $0.01-45$ \\
$\gamma$ & Coefficient lag-time relationship & $/$ & $0.5-3.5$ \\
$\mathrm{Kc}$ & Parameter of potential evapotranspiration & $/$ & $0.4-2$ \\
$\alpha$ & Exponent of the infiltration relationship & $/$ & $1-15$ \\
\hline
\end{tabular}

\subsection{Sensitivity Test}

In order to understand the sensitiveness of model parameters and model behaviors, we conducted a local sensitivity analysis, where parameters' values are varied 6 times with equal intervals within the parameter boundaries. This operation was performed for each parameter and each single flood event. The parameter sensitiveness was estimated by the mean of maximum difference of the 6 runs averaged over time across all 15 events. We also performed sensitivity tests for the case including the W_max parameter in calibration because W_max dominates the infiltration process in small to medium catchments, which controls the runoff generation in flood models but it is not calibrated in the MISDc-2L model by default [42]. The parameter value was set as a constant value of 150 by default in previous studies, according to the spatial distribution of the Curve Number values were computed from soil/land use characteristics and scaling factor based on assumptions about its variety in space by experience and the specific catchments $[21,43]$. This parameter value was empirically determined from flood events for the catchments in limited study areas and may be inappropriate in other areas or catchments. Hence, it is necessary to assess the impact of W_max calibration on flood simulation.

Figure 2 shows the changes in simulation due to parameter sampling for both cases including or excluding W_max for calibration. Among 10 given parameters, 5 parameters $\left(\gamma, W \_p, K s, \alpha\right.$, and Kc) are sensitive, whereas 4 parameters (W_max2, Ks2, $\mathrm{m}$ and $\mathrm{m} 2$ ) are less sensitive or insensitive. For the case calibrating W_max, it led to changes in the sensitiveness of other model parameters. For example, $\mathrm{Ks}, \gamma, \mathrm{Kc}$ became less sensitive while W_p became more sensitive. $\gamma$ is the most sensitive parameter in the case without $W \_m a x$ calibration, while $W \_p$ is the most sensitive parameter in the case including W_max calibration. These differences can be explained by the fact that the $W \_m a x$ calibration influences the relationship between variables of routine in water balance functions (e.g., main routine) and direct runoff functions (e.g., dynamic parameter lag time).

We further investigated the influence on other parameters after including the W_max parameter in the calibration by performing "split-sample" tests for calibration and validation scenarios (Figure 3). The influence of W_max calibration on other parameters resulted in sensitiveness of parameter Ks, and Ks2 strongly varied with the opposite trend compared to W_max. This means that W_max is an important parameter in the MISDc-2L model, which substantially influences model performance, and thus needs to be treated carefully.

We also investigated the influence of parameter range of W_max on calibration performance by running model with changed W_max ranges for the low and the high boundary as 10 700 and 50 350, respectively. It showed that range changes had relatively small impact on model performance, as the calibrated values were not confined by boundaries. 


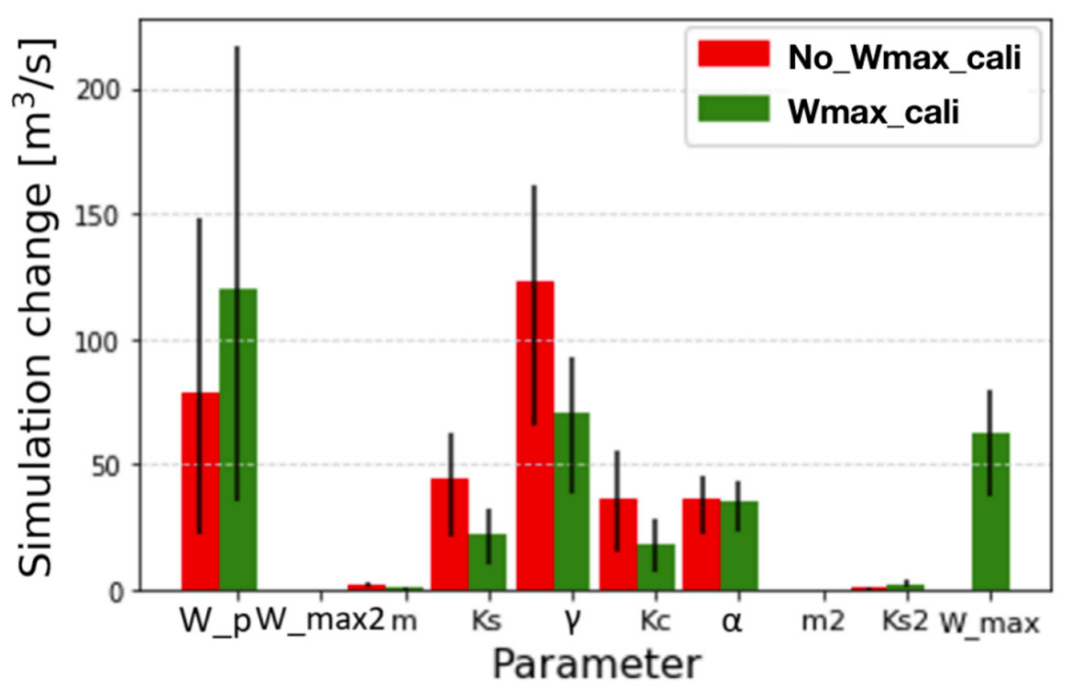

Figure 2. Simulation changes from sensitivity tests of model parameters in the cases without and with W_max calibration across 15 individual flood event runs.
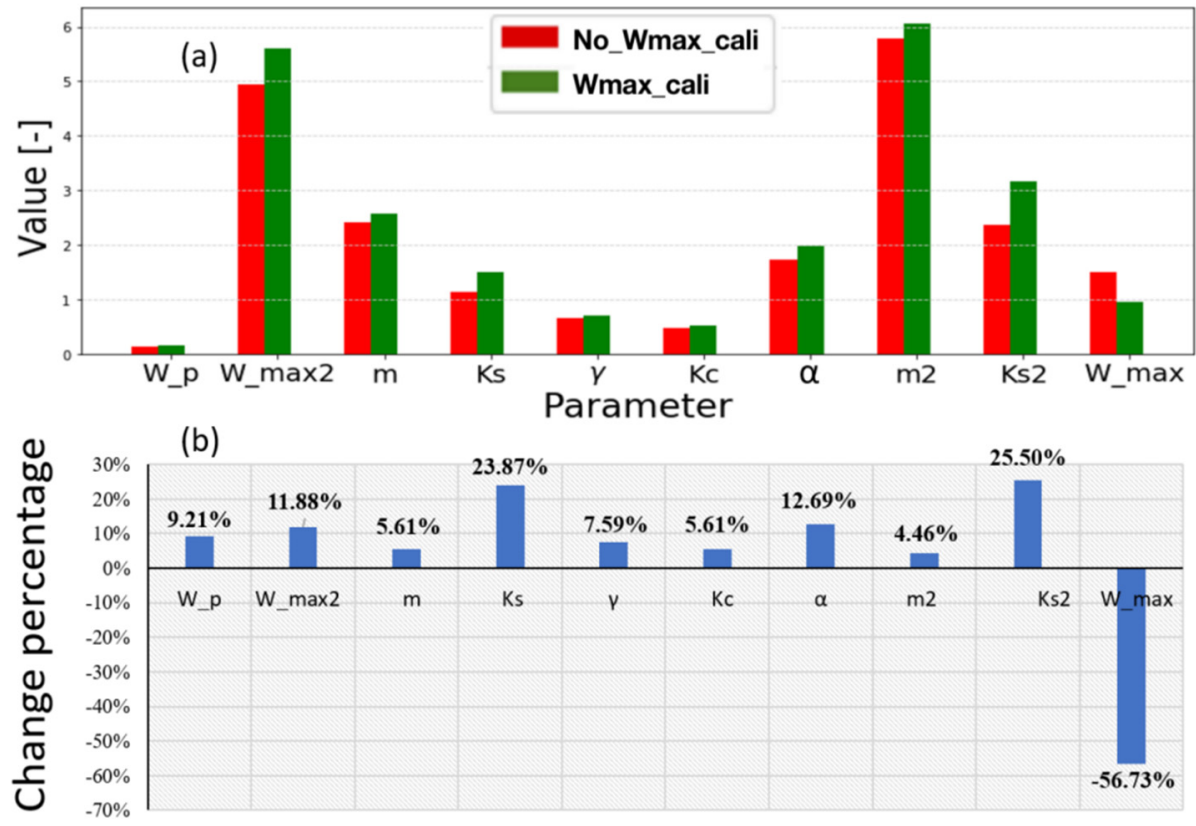

Figure 3. Influence on other parameters by the inclusion of calibration of W_max: (a) absolute change (note that W_max2 and W_max were scaled with 0.01 for plotting), and (b) change percentage.

\subsection{Model Calibration and Validation}

We tested different calibration schemes with the available data record from 2010 to 2015 . First, the model was calibrated with full parameters set (9 parameters) with respect to the original model setup, namely as Scheme 1 (S1). According to sensitivity test, the calibration scheme using partial parameters set ( 5 parameters) was proposed, whereby the amount of calibration parameter was 5 , namely as Scheme 2 (S2). Herein, the sensitive parameters were automatically calibrated and insensitive parameters were given values within their boundaries. Furthermore, to investigate the role of W_max calibration in flood simulation, another calibration scheme was carried out, in which the W_max parameter was extendedly included and the total calibration parameter amount was 6 ; this was named as Scheme 3 (S3). The calibration schemes are summarized in Table 4. Each calibration scheme was run for different calibration experiments, including 15 single events, a "split-sample" test splitting event data into a calibration period (10 events) and a validation period ( 5 events), as well as "combined 
multiple-events samples" according to magnitude levels with 7 high-flow events, 7 medium-flow events and 7 low-flow events for both calibration and validation. The aim was to avoid the mismatch between characteristics of selected flood events due to insufficient length of study period in presenting the different climatic conditions in calibration and validation periods $[44,45]$. The flowchart of this study is presented in Figure 4.

Table 4. Calibration schemes using the MISDc-2L model.

\begin{tabular}{ccc}
\hline Scheme & Description & Parameters for Calibration \\
\hline S1 & Calibration with 9 parameters & W_max2, W_p, m, m2, Ks, Ks2, $\gamma, \mathrm{Kc}, \alpha$ \\
S2 & Calibration with 5 parameters & $\gamma, \mathrm{W} \_\mathrm{p}, \mathrm{Ks}, \alpha, \mathrm{Kc}$ \\
S3 & Calibration with 6 parameters & $\gamma, \mathrm{W}$-p, Ks, $\alpha, \mathrm{Kc}, \mathrm{W}$ _max \\
\hline
\end{tabular}

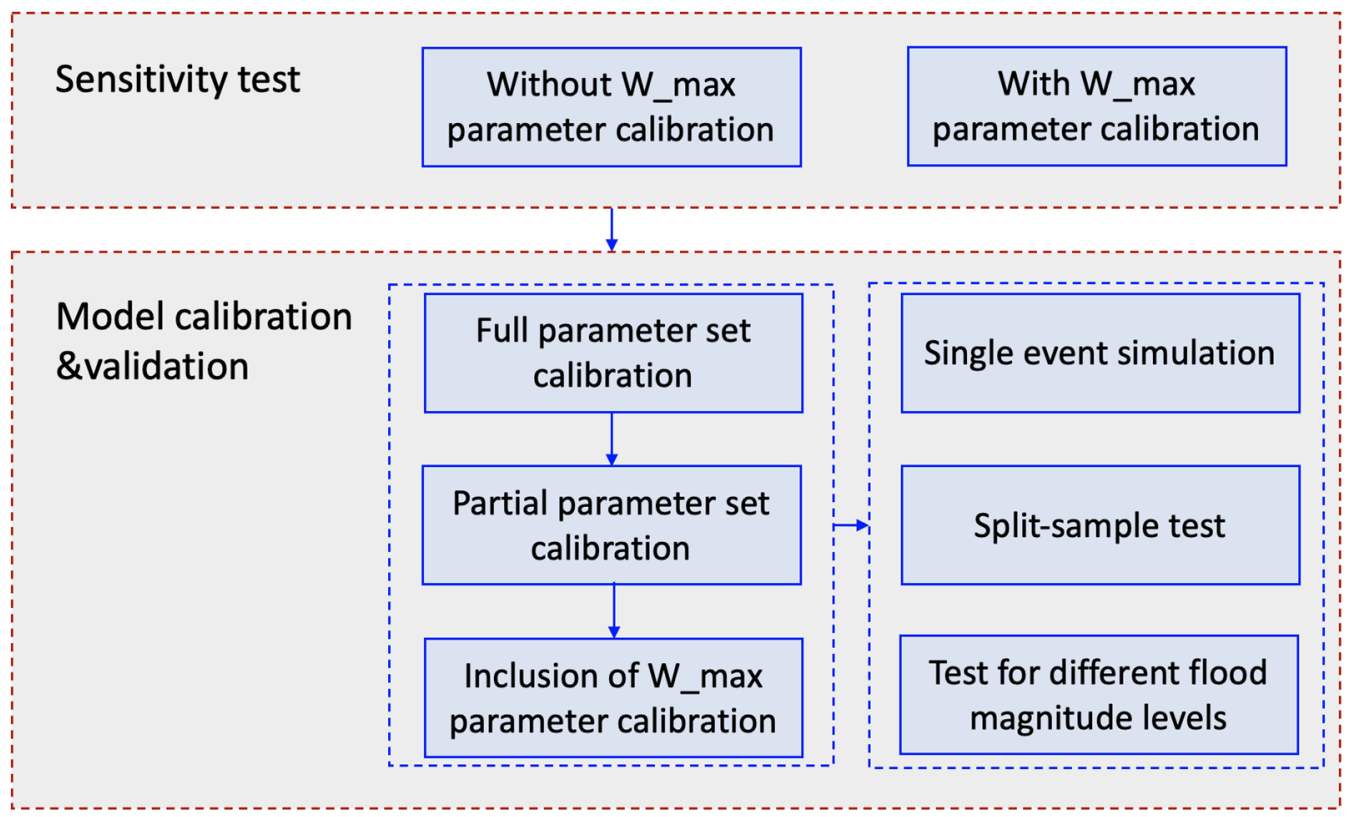

Figure 4. Flowchart of this study.

In terms of calibration method, the "fmicon" function in MATLAB was used, which is based on a local search optimization algorithm, due to its simplicity, requiring non-professional skill, low computation and less parameters compared to the global optimization method.

The Kling-Gupta efficiency (KGE) was chosen as an objective function from the derived NSE criterion in order to avoid the problem of high sensitivity to extreme values and bias Kling et al. [46]. KGE is presented as follows:

$$
\mathrm{KGE}=1-\sqrt{(\mathrm{r}-1)^{2}+(\beta-1)^{2}+(\delta-1)^{2}}
$$

where $r$ represents Pearson's correlation coefficient, and $\beta$ is the ratio between the mean of the modeled variable and the mean of the observed variable, $\delta$ is the variation coefficient ratio.

The model simulations were evaluated using three metrics, namely the coefficient of determination $\left(\mathrm{R}^{2}\right)$, the percentage error on peak discharge $\left(E_{Q p}\right)$, the percentage error on the flood volume. The metrics are, respectively, shown in Formulas (2) to (4):

$$
\mathrm{R}^{2}=\frac{\sum_{t=1}^{N_{t}}\left(Q_{o b s}-\overline{Q_{o b s}}\right)\left(Q_{s i m}-\overline{Q_{s i m}}\right)^{2}}{\sum_{t=1}^{N_{t}}\left[\left(Q_{o b s}-\overline{Q_{o b s}}\right)^{2}\left(Q_{s i m}-\overline{Q_{s i m}}\right)^{2}\right]}
$$




$$
\begin{gathered}
\mathrm{E}_{\mathrm{Qp}}=100 \frac{\max \left(Q_{o b s}\right)-\max \left(Q_{\text {sim }}\right)}{\max \left(Q_{o b s}\right)} \\
\mathrm{E}_{\mathrm{V}}=\frac{\sum_{t}^{T_{e V}} Q_{o b s}-\sum_{t}^{T_{e V}} Q_{s i m}}{\sum_{t}^{T_{e V}} Q_{o b s}}
\end{gathered}
$$

where $Q_{o b s}$ and $Q_{s i m}$ are the observed and simulated discharges, respectively, and $\overline{Q_{o b s}}$ is the mean value of observed discharge series during the event and $T_{e V}$ is the event duration. The sum is counted for the length $N_{t}$ of the observed, $Q_{o b s}$, and simulated $Q_{\text {sim }}$, discharge vectors.

\section{Results}

\subsection{Full versus Partial Parameter Set Calibration Strategies for Flood Simulations}

In the case in which W_max was not calibrated, two different parameter set calibration strategies (full or partial) were compared for 15 single flood events (Figure 5). The full parameter scheme (Scheme 1, S1) calibrates all nine parameters and the partial scheme (Scheme 2, S2) calibrates five selected parameters. Overall, the model performed better for the flood events with narrow, steep and single-peak hydrographs than those with multiple peaks. The model run with S1 tended to underestimate the base-flow of flood events, while it was obvious that the model using the S2 scheme better captured the hydrographs of flood events and simulated base-flows accurately (highlighted by the blue dashed box in Figure 5). Moreover, as indicated by the evaluation indexes (Figure 6), Scheme S2 significantly outperformed S1, which substantially improved the simulations for all flood events. The mean $R^{2}$ and KGE were 0.56 and 0.41 for S1 while increasing to 0.70 and 0.66 for S2, respectively. The error indexes $\left(\mathrm{E}_{\mathrm{Qp}}\right.$ and $\left.\mathrm{E}_{\mathrm{v}}\right)$ of $\mathrm{S} 2$ indicated that the simulations agree well with the observations and their values were smaller than $20 \%$. The average error of flood peak $\left(\mathrm{E}_{\mathrm{Qp}}\right)$ of $\mathrm{S} 2$ with respect to the same values of S1 slightly increased from $12.87 \%$ to $15.67 \%$, whereas the average error of flood volume $\left(\mathrm{E}_{\mathrm{V}}\right)$ significantly reduced from $49.87 \%$ to $2.08 \%$. These results suggest that the calibration parameter selection is very important for flood simulations, and it is critical to select a suitable parameter set to reduce the uncertainty in parameter identifiability.

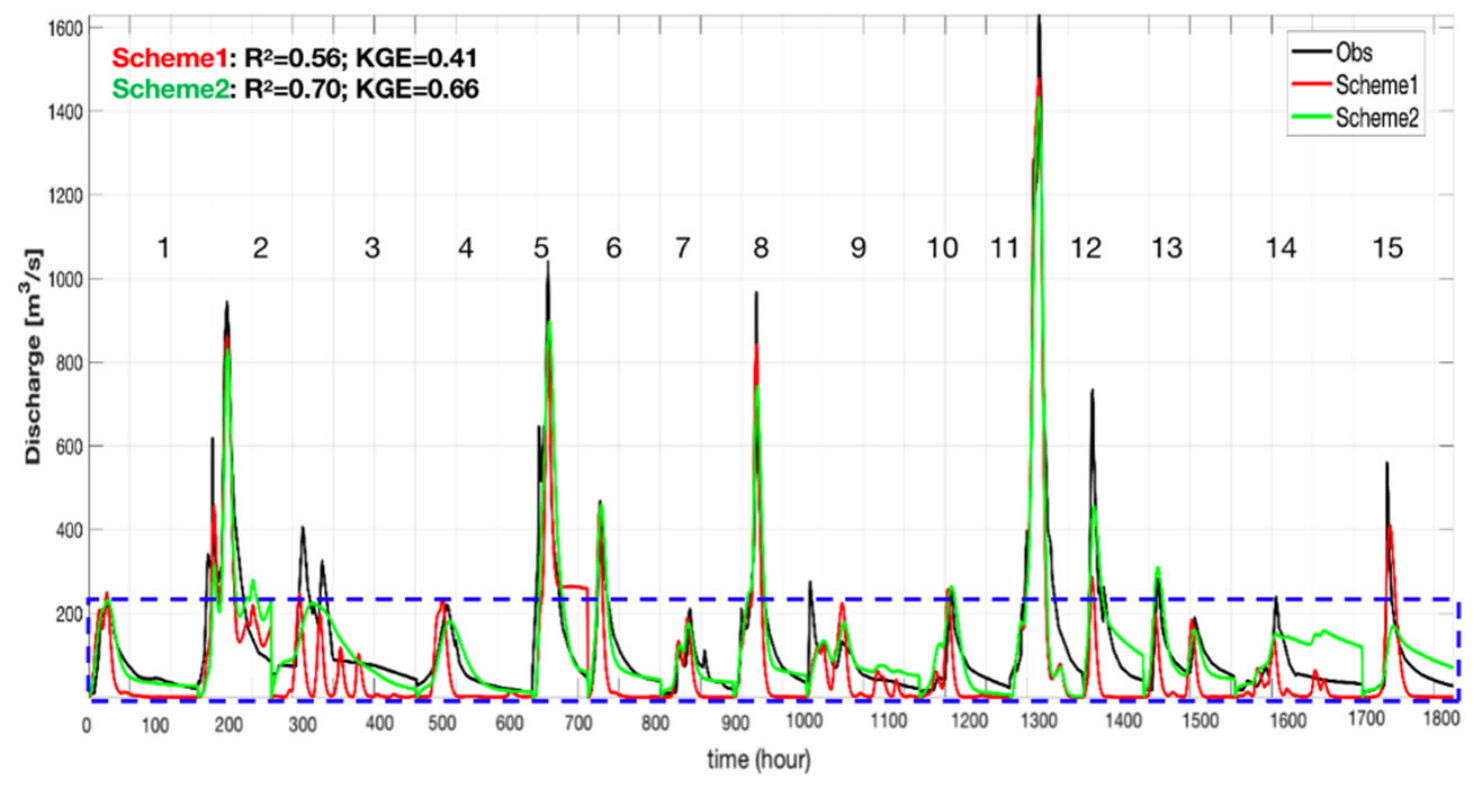

Figure 5. Comparison between observed and simulated streamflow with calibration scheme 1 versus scheme 2. The dashed blue box highlights significant improvements of base-flow simulation from scheme 1 versus scheme 2 . 


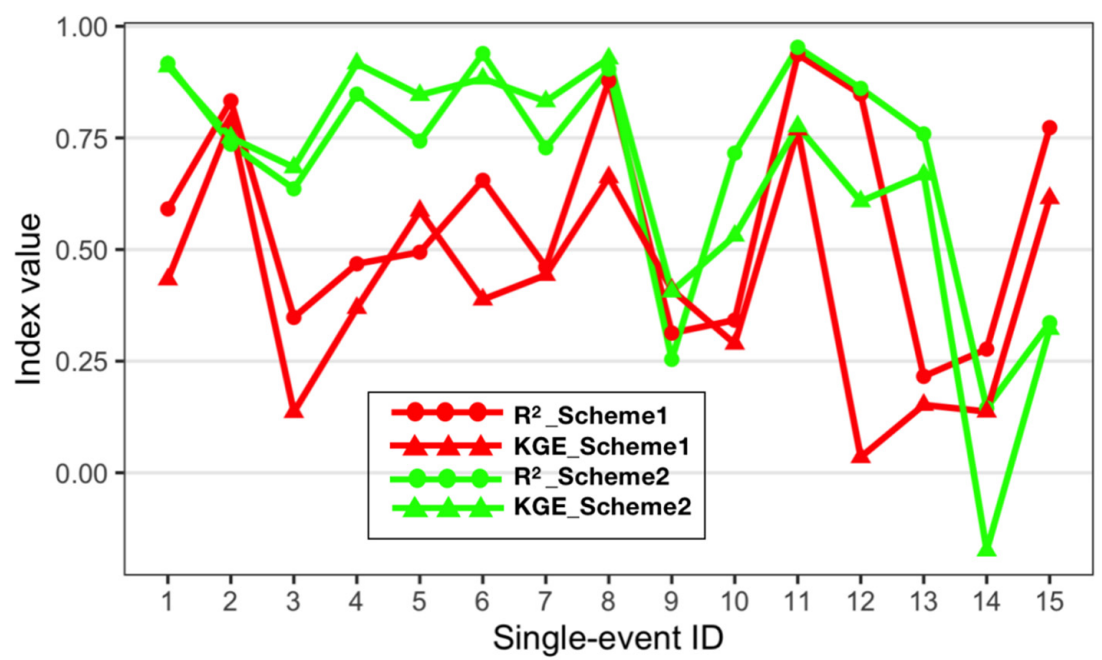

Figure 6. Evaluation index comparison between observed and simulated streamflow with calibration scheme 1 versus scheme 2 .

\subsection{Impact of $W \_m a x$ Calibration on Flood Simulations}

Here, the role of W_max calibration was explored by the comparison of model performances between calibration schemes S2 and S3 for single event simulations (Section 3.4) (Figure 7). Generally, in both cases the model captured the hydrographs and peaks of flood events. Obviously, the simulation run with S3 captured the hydrographs, the peaks of floods and base-flow more accurately (Figure 7). In particular, the model using S3 simulated accurately for medium-flow and low-flow events while the model using S2 performed poorly. For example, for event 3, 12, 14 and 15 , the $\mathrm{R}^{2}$ for S3 increased by $23.6 \%, 7.8 \%, 65.7 \%$, and $41.1 \%$ and reached $0.87,0.94,0.80$, and 0.75 , respectively, and KGE values also improved remarkably by $12.7 \%, 36 \%, 104.8 \%$, and $52.8 \%$ compared to those of S2 and reached 0.81 , $0.97,0.87$ and 0.85 , respectively (Figure 8). Overall, the average $\mathrm{R}^{2}$ and KGE of S2 were 0.70 and 0.66 , while those of S3 increased to 0.81 and 0.82 , respectively. For the average error indexes on flood peak $\left(\mathrm{E}_{\mathrm{Qp}}\right)$ and flood volume $\left(\mathrm{E}_{\mathrm{v}}\right)$ of $\mathrm{S} 3$, the indexes considerably reduced from $15.67 \%$ to $7.38 \%$ and $-2.07 \%$ to $0.49 \%$ compared to $\mathrm{S} 2$, respectively. It is clear that S3 outperformed S2, indicating that it is beneficial to include the $\mathrm{W} \_$max parameter in the calibration procedure.

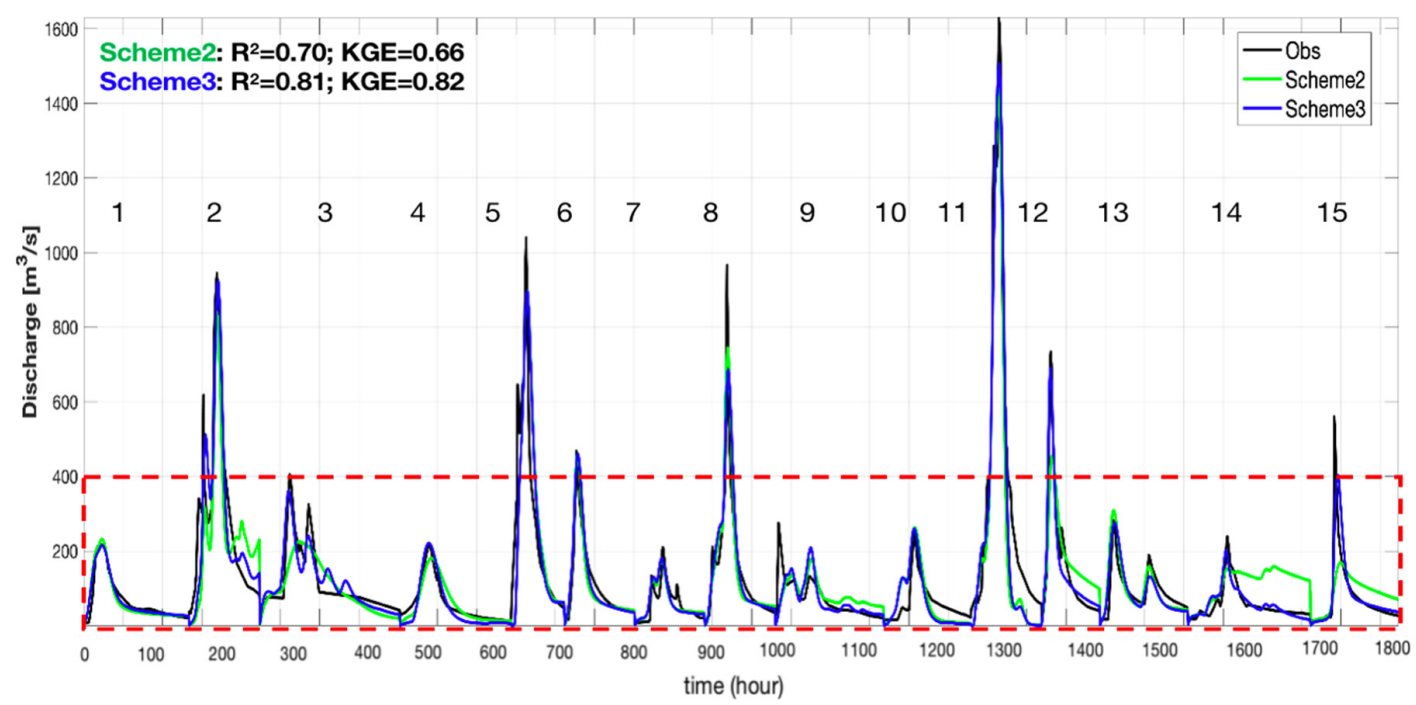

Figure 7. Comparison between observed and simulated streamflow accounting for W_max calibration (S3) versus without W_max calibration (S2). The dashed red box highlights significant improvements of base-flow simulation from scheme 2 versus scheme 3 . 


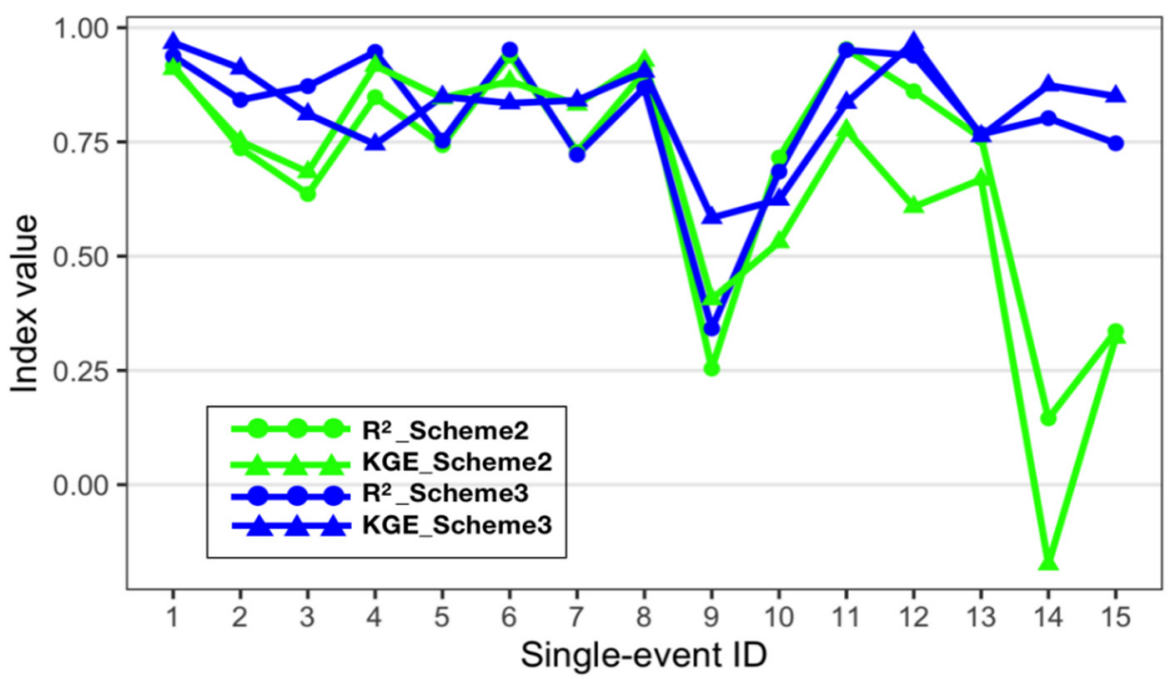

Figure 8. Index comparison between observed and simulated streamflow with calibration scheme 2 versus scheme 3 .

\subsection{Comparison of Different Calibration Schemes for Flood Simulations with "Split-Sample" Test}

The observed and simulated discharges with the original calibration scheme (S1) and the new calibration schemes without (S2) and with W_max calibration (S3) are shown in Figure 8. It is obvious that the model using calibration S2 and S3 outperformed S1. The model run with S1 was only able to satisfactorily simulate the high-flow flood events, but not the base-flow ones, while the model with S2 and S3 simulated the base-flow process much better (Figure 9a,c). Evaluation indexes were lowest for $\mathrm{S} 1\left(\mathrm{R}^{2}=0.67\right.$ and KGE $=0.67$ for calibration, $\mathrm{R}^{2}=0.82$ and KGE $=0.63$ for validation), while these values increased clearly for $S 2\left(R^{2}=0.61\right.$ and KGE $=0.74$ for calibration, $R^{2}=0.84$ and $\mathrm{KGE}=0.83$ for validation), and the indexes reached the highest levels for $\mathrm{S} 3\left(\mathrm{R}^{2}=0.66\right.$ and $\mathrm{KGE}=0.78$ for calibration, $R^{2}=0.85$ and $K G E=0.89$ for validation) (Table 5). It is worth noting that the evaluation indexes of the validation process were generally higher than those of the calibration process for all three calibration schemes. These results demonstrated the model's robustness in continuous prediction of the flood-events in the future. The differences simulation between the three schemes, especially for base-flow simulation, were also illustrated clearly by scatter plots (Figure $9 b, d$ ), where model simulations of S1 were distributed far from the observations, especially for base-flow simulation, while S2 and S3 simulations were closer to observations. According to the distances from the diagonal of the scatter-plots, we observed that calibration schemes S2 and S3 with fewer calibration parameters archived better performances, and including W_max calibration led to the best performance.

Table 5. Comparison of the average $\mathrm{R}^{2}$ and KGE for different magnitudes of multiple schemes.

\begin{tabular}{ccccc}
\hline \multirow{2}{*}{ Scheme } & \multicolumn{2}{c}{ Calibration } & \multicolumn{2}{c}{ Validation } \\
\cline { 2 - 5 } & $\mathbf{R}^{\mathbf{2}}$ & KGE & $\mathbf{R}^{\mathbf{2}}$ & KGE \\
\hline S1 & 0.67 & 0.67 & 0.82 & 0.63 \\
S2 & 0.61 & 0.74 & 0.84 & 0.83 \\
S3 & 0.66 & 0.78 & 0.85 & 0.89 \\
\hline
\end{tabular}



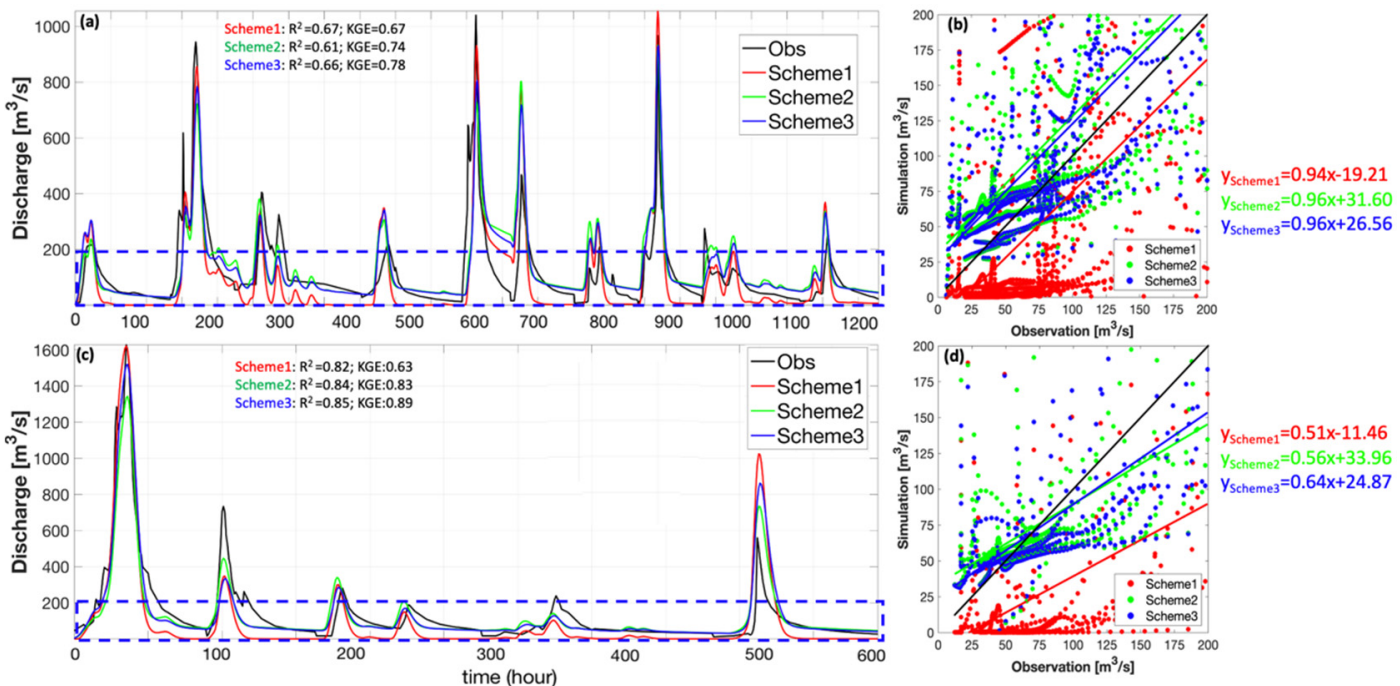

Figure 9. Comparison between observed and simulated streamflow with calibration scheme 1, scheme 2 and scheme 3 , subplots (a) and (b) are for calibration and subplots (c) and (d) are for validation. The dashed blue boxes highlight base-flow simulation, which are presented by scatter plots (b) and (d).

\subsection{Model Performance of Flood Simulations for Different Magnitude Levels}

We performed combined flood event simulations (called "combined-event" experiment) at different magnitude levels, including seven high-magnitude events (events 1-7), seven medium-magnitude events (events 8-14) and seven low-magnitude events (events 15-21). The magnitude of flood events had evident impact on model simulation. It is obvious that the model performed best for those high-magnitude combined-events, followed by the low and medium magnitude levels of flood events for both calibration and validation across all schemes (Figure 10). The evaluation indexes of S3 and S2 were clearly higher than S1 for all magnitude levels of flood events (Table 6). The most significant improvements were found for medium magnitude events in the model simulations with S3, which showed the worst performance using S1. Compared to S1, the evaluation indexes of S3 remarkably increased by $40 \%$ in $\mathrm{R}^{2}$ and $39 \%$ in KGE for calibration, and $44 \%$ in $\mathrm{R}^{2}$ and $39 \%$ in KGE for validation. These indexes for low magnitude events increased by $31 \%$ in $R^{2}$ and $26 \%$ in KGE for calibration, and $40 \%$ in $\mathrm{R}^{2}$ and $22 \%$ in KGE for validation, while these indexes of high-magnitude slightly increased by $6 \%$ in $\mathrm{R}^{2}$ and $5 \%$ in KGE for calibration, and $6 \%$ in $\mathrm{R}^{2}$ and $11 \%$ in KGE for validation. From the above analyses, it is further confirmed that the inclusion of the $\mathrm{W} \_$max parameter in the calibration process is beneficial for flood simulations, especially for medium and low magnitude levels of flood events.

Table 6. Comparison of average $\mathrm{R}^{2}$ and KGE for different magnitude levels of flood events with three different calibration schemes.

\begin{tabular}{cccccc}
\hline \multirow{2}{*}{ Magnitude } & \multirow{2}{*}{ Scheme } & \multicolumn{2}{c}{ Calibration } & \multicolumn{2}{c}{ Validation } \\
\cline { 3 - 6 } & & $\mathbf{R}^{\mathbf{2}}$ & KGE & $\mathbf{R}^{\mathbf{2}}$ & KGE \\
\hline \multirow{2}{*}{ High-magnitude } & $\mathrm{S} 1$ & 0.66 & 0.76 & 0.65 & 0.61 \\
(Events 1-7) & $\mathrm{S} 2$ & 0.70 & 0.81 & 0.65 & 0.68 \\
& $\mathrm{~S} 3$ & 0.72 & 0.82 & 0.70 & 0.72 \\
\hline \multirow{2}{*}{ Medium-magnitude } & $\mathrm{S} 1$ & 0.28 & 0.29 & 0.22 & 0.12 \\
(Events 8-14) & $\mathrm{S} 2$ & 0.65 & 0.76 & 0.40 & 0.14 \\
& $\mathrm{~S} 3$ & 0.68 & 0.73 & 0.61 & 0.51 \\
\hline \multirow{2}{*}{ Low-magnitude } & $\mathrm{S} 1$ & 0.42 & 0.35 & 0.44 & 0.32 \\
(Events 15-21) & $\mathrm{S} 2$ & 0.77 & 0.70 & 0.70 & 0.47 \\
& $\mathrm{~S} 3$ & 0.73 & 0.75 & 0.70 & 0.54 \\
\hline
\end{tabular}



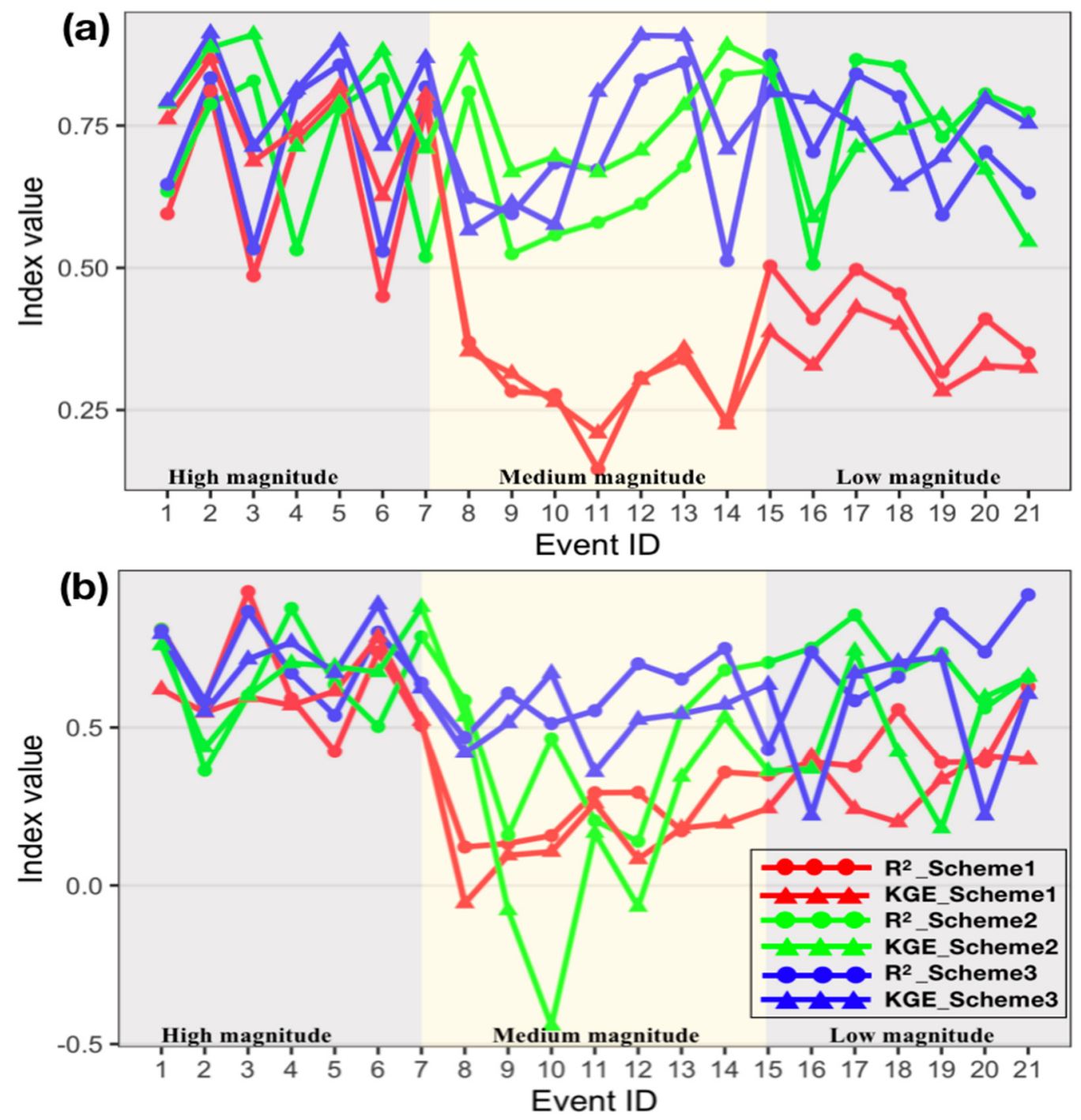

Figure 10. Performance index comparison for the simulations of different magnitude levels of flood events with three different calibration schemes: (a) calibration, (b) validation.

\section{Discussion}

\subsection{The Impact of Parameter Reduction of the Calibration Process on Flood Simulation}

The calibration process plays a vital role in hydrological models; however, uncertainties from model parameters is one of the main factors that hamper the simulation $[47,48]$. One method to alleviate model calibration uncertainty is to reduce parameter dimensionality before calibration, where only sensitive parameters are automatically calibrated and insensitive parameters are given values within their boundary to determine the best set of parameters for flood simulation. Son et al. [49] argued that reducing the number of calibration parameters might make it impossible to present critical processes. However, even after calibration, a significant amount of uncertainties in the results could occur, such as the values of the calibrated parameters not realistically reflecting watershed characteristics or equifinality of parameter sets, leading to similar results when many parameters interact in the calibration process $[27,28]$. A number of studies declared that expert knowledge of the physical meaning of parameters and understanding about the role of each parameter are important ways to select suitable parameters for calibration, instead of using full parameter sets [50-52]. Muleta et al. [50] used different techniques to determine the parameters of the SWAT model for calibration, whereby the number of parameters for calibration was reduced to 20, and van Werkhoven et al. [51] used the 
SAC-SMA model with the calibration parameters reduced from 14 to 6 and 5 according to sensitivity analysis. The authors stated that the selection of parameters for the calibration process should be different across the catchments because the sets of sensitive parameters are inconsistent between cases. This is likely true with the MISDc-2L model, whereby in this study the model performed better with reduced calibration parameters compared to the full calibration parameter set used in previous studies.

\subsection{The Importance of W_Max Parameter Estimation in Flood Simulation}

In hydrological operation, infiltration is the most important water loss during flash floods, and a good understanding of infiltration is crucial for an appropriate representation of runoff generation and losses [53]. Attempts to improve the infiltration process were made by previous studies $[26,30,53,54]$. Liu et al. [26] modified the Green-Ampt equation in the MISDc model to improve flood simulation with fixed values of the maximum water capacity parameter (W_max) but the improvement was minuscule, where the evaluation index (NSE) increased from 0.71 to 0.73 . In this study, in an attempt to improve the infiltration process, the emphasis on the impact of W_max calibration was carried out due to its important role in estimating infiltration capacity, which influences the calculation of runoff generation [55]. The improvements were obvious, where the evaluation indexes increased from 0.56 to 0.81 for $\mathrm{R}^{2}$ and from 0.41 to 0.82 for KGE. This indicates that accurately estimating the key parameter is a useful method to improve infiltration process estimation in flood simulation.

In order to confirm the important role of W_max estimation in the MISDc-2L model, we extendedly repeated our experiments on another three semi-humid catchments in the Huai River, namely Huangwei, Qishan and Qling, with drainage areas of $269.8 \mathrm{~km}^{2}, 405 \mathrm{~km}^{2}$ and $181.7 \mathrm{~km}^{2}$, respectively. The results clearly indicated that the model performed better when calibrating W_max and improvements due to including W_max for calibration were also found for different magnitude levels of flood events, where the model performed best for high-magnitude events and poorer for medium and low events. These findings are consistent with those in the Huangnizhuang catchment, confirming the fundamental role of W_max calibration for improving flood simulation.

\subsection{The Influence of Objective Function on Flood Simulations}

The choice of objective function obviously plays an important role in the evaluation of model performance and considerably influences the quality of flood simulations [56]. We chose the Kling-Gupta efficiency (KGE) as objective function for this study after acknowledging the advantages of different statistical indexes. For example, compared to one commonly used index, the Nash-Sutcliffe efficiency (NSE), the KGE correctly estimates the variability and directly assesses four aspects of discharge such as time series, hydrograph, timing, water balance and variability [46,57-60]. Gupta et al. [60] reported clear improvement of flow variability estimates by switching the calibration metric from NSE to KGE for a simple rainfall-runoff model similar to the HBV model. Similarly, Mizukami, Rakovec, Newman, Clark, Wood, Gupta and Kumar [56] also reported the same results from two relatively more complex models. In addition, we have examined the model performances under two objective functions, KGE and NSE. The results in our study showed that the simulations using KGE as an objective function were generally better than those using NSE in terms of performance index statistics and flood simulation hydrographs. This is consistent with previous studies and confirmed that it is suitable to use KGE as an objective function for our study.

Mathevet, T. et al. [61] raised the issue about the performance of KGE in long-term analysis. Although KGE is usually preferable for the general optimization of hydrodrological models in short term analysis, its applicability for long-term analysis is unclear. In this study, the assessment of long-term analysis was not made because of data limitation.

\subsection{Other Issues Related to Flood Simulations}

The quality and quantity of rainfall data are quite important for flood simulation. Our study used hourly rainfall gauged input data to simulate runoff in a small mountainous catchment area. Due to its 
complex topography and high variability of precipitation, there are usually not enough rain-gauge stations to assure the accuracy of areal precipitation assessment. In our study, the rain-gauge density is only about $100 \mathrm{~km}^{2}$ per station and not always continuously recorded at hourly steps. In some cases, the event was not well captured by the model, which was likely attributed to the catchment's complex topography and partly to the the missing of hourly observation data. Recently, several satellite rainfall datasets were developed as a potential alternative to the rain-gauge data. Camici, S. et al. [62] reported that improvements to runoff simulation can be achieved by applying a satellite rainfall product, SM2RAIN-ASCAT [63], to force the MISDc model. However, current satellite rainfall data are usually available at daily resolution with low spatial resolution, which are not applicable for hourly runoff simulation in fine-scale catchments. Usually, appropriate approaches for upscaling and interpolation are required to remedy the spatiotemporal resolution gaps. Therefore, it would be a promising avenue to integrate satellite rainfall and soil moisture data into our model for improving flood forecast, which is the goal of our ongoing study.

In addition, the interpolation method for rainfall data is also one source of uncertainty. Different interpolation methods are suitable for different variables, rain-gauge station densities and climate regimes $[8,64]$. We chose the IDW method for this study after investigating the advances and weaknesses of different methods. For example, compared to one commonly used interpolation method, Thiessen Polygons, the IDW method could be more suitable for rainfall interpolation in mountainous areas.

Lastly, we do not account for the uncertainty linked to rainfall phenomena and the uncertainty linked to hydraulics because of the model limitation in this study. The MISDc-2L model does not couple with hydraulic modules, so we cannot account for such uncertainty related to these aspects under the current model framework. Integration of the Ensemble Prediction System (EPS) and data assimilation techniques could be useful for better accounting for such uncertainties [65-67].

It's well-known that rain-runoff model is usually a core component of early warning systems (EWS) for flash floods. The MISDc-2L model has a parsimonious structure, making it easy for operational use and understanding by end users. With careful calibration parameter selection, we proved the robustness of the model in flash flood prediction, which could increase possible lead time for EWS. Crucial predictive information from EWS would help decision makers and stakeholders to gain more time for preparing, avoiding and reducing the losses and damages from flash floods. Our findings would therefore have important implications for flash flood predictions and robust EWS establishment.

\section{Conclusions}

In this study, we investigated the influence of calibration parameter selection on flash flood simulation for small to medium catchments with the MISDc-2L model in the Huai River basin of China over the 2010-2015 period. We explored the necessity of reducing calibration parameters and the role of W_max parameter calibration for flood simulations. The role of the W_max parameter for single events, split-sample tests and combined-events, and for different magnitude levels of flood, were investigated.

Although it is quite challenging to simulate floods in small to medium catchments in semi-humid areas, in our study the MISDc-2L model has satisfactory performance after reducing calibration parameters and including the W_max parameter for calibration. The results confirmed the finding that lumped models with suitable calibration strategies can effectively simulate flash floods in small to medium catchments (SMC). The reduction in calibration parameters' amount is confirmed to remarkably improve streamflow simulation. In addition, we found that the inclusion of calibration of the parameter W_max in the infiltration process is crucial for streamflow simulation, especially for base flow, and it needs to be treated carefully for calibration. Model performances varied with flood magnitude levels and the simulations are generally better for high-magnitude floods than medium and low ones, but clear improvements can be achieved for low and medium magnitude flood events with careful calibration parameter selection. Therefore, improving the understanding of physical meanings of parameters as well as their roles in model simulation is highly necessary to build better calibration 
schemes, which are beneficial in terms of enhancing the accuracy of flood prediction and thus better serve early warning systems.

It is important to note that MISDc-2L performance in this study was limited by the length of the available data records (only 6 years of flood-events) and uncertainty from hourly rainfall input data associated with low rain-gauge density in small mountainous catchments, which could lead to the errors on the runoff generation. Thus, the methods for improving the quality and quantity of rainfall data should be given more attention in future.

Author Contributions: N.T.N. and H.L. designed the study, and N.T.N. and W.H. conducted data preparation and model setup; N.T.N., W.H., Y.Z. and H.L. conducted results analysis and discussion; N.T.N. and W.H. drafted the manuscript of the article; All authors reviewed the manuscript and contributed to editing. All authors have read and agreed to the published version of the manuscript.

Funding: This research was funded by National Key Research and Development Program (Grant No. 2019YFC1510504) and the National Natural Science Foundation of China (Grant Nos. 41830752 and 41961134003 ). W.H. is funded by the National Natural Science Foundation of China (Grant No. 41907378).

Acknowledgments: We sincerely acknowledge Luca Brocca and Christian Massari from the Research Institute for Geo-Hydrological Protection of the Italian National Research Council for sharing the source code of the MISDc-2L model. We also sincerely acknowledge the Bureau of Hydrology, Ministry of Water Resources China for providing the river discharge data, and the Meteorological Data Service Center of China Meteorological Administration for providing the CLDAS version 2.0 data.

Conflicts of Interest: The authors declare no conflict of interest.

\section{References}

1. Gaume, E.; Borga, M.; Llassat, M.C.; Maouche, S.; Lang, M.; Diakakis, M. Mediterranean Extreme Floods and Flash Floods; IRD Editions: Marseille, France, 2016.

2. Ragettli, S.; Zhou, J.; Wang, H.; Liu, C.; Guo, L. Modeling flash floods in ungauged mountain catchments of China: A decision tree learning approach for parameter regionalization. J. Hydrol. 2017, 555, 330-346. [CrossRef]

3. Tramblay, Y.; Bouvier, C.; Ayral, P.-A.; Marchandise, A. Impact of rainfall spatial distribution on rainfall-runoff modelling efficiency and initial soil moisture conditions estimation. Nat. Hazards Earth Syst. Sci. 2011, 11, 157-170. [CrossRef]

4. Brocca, L.; Liersch, S.; Melone, F.; Moramarco, T.; Volk, M. Application of a model-based rainfall-runoff database as efficient tool for flood risk management. Hydrol. Earth Syst. Sci. 2013, 17, 3159-3169. [CrossRef]

5. Wang, Y.; Liu, R.; Guo, L.; Tian, J.; Zhang, X.; Ding, L.; Wang, C.; Shang, Y. Forecasting and Providing Warnings of Flash Floods for Ungauged Mountainous Areas Based on a Distributed Hydrological Model. Water 2017, 9, 776. [CrossRef]

6. Yin, J.; Gentine, P.; Zhou, S.; Sullivan, S.C.; Wang, R.; Zhang, Y.; Guo, S. Large increase in global storm runoff extremes driven by climate and anthropogenic changes. Nat. Commun. 2018, 9, 4389. [CrossRef] [PubMed]

7. Karymbalis, E.; Katsafados, P.; Chalkias, C.; Gaki-Papanastassiou, K. An integrated study for the evaluation of natural and anthropogenic causes of flooding in small catchments based on geomorphological and meteorological data and modeling techniques: The case of the Xerias torrent (Corinth, Greece). Z. Geomorphol. Suppl. Issues 2012, 56, 45-67. [CrossRef]

8. Kobold, M.; Brilly, M. The use of HBV model for flash flood forecasting. Nat. Hazards Earth Syst. Sci. 2006, 6, 407-417. [CrossRef]

9. Tegegne, G.; Park, D.K.; Kim, Y.-O. Comparison of hydrological models for the assessment of water resources in a data-scarce region, the Upper Blue Nile River Basin. J. Hydrol. Reg. Stud. 2017, 14, 49-66. [CrossRef]

10. Das, T.; Bárdossy, A.; Zehe, E.; He, Y. Comparison of conceptual model performance using different representations of spatial variability. J. Hydrol. 2008, 356, 106-118. [CrossRef]

11. Lobligeois, F.; Andréassian, V.; Perrin, C.; Tabary, P.; Loumagne, C. When does higher spatial resolution rainfall information improve streamflow simulation? An evaluation using 3620 flood events. Hydrol. Earth Syst. Sci. 2014, 18, 575-594. [CrossRef]

12. Boithias, L.; Sauvage, S.; Lenica, A.; Roux, H.; Abbaspour, K.C.; Larnier, K.; Dartus, D.; Sánchez-Pérez, J.M. Simulating Flash Floods at Hourly Time-Step Using the SWAT Model. Water 2017, 9, 929. [CrossRef] 
13. Li, D.; Qu, S.; Shi, P.; Chen, X.; Xue, F.; Gou, J.; Zhang, W. Development and Integration of Sub-Daily Flood Modelling Capability within the SWAT Model and a Comparison with XAJ Model. Water 2018, 10, 1263. [CrossRef]

14. Huang, Y.; Bárdossy, A.; Zhang, K. Sensitivity of hydrological models to temporal and spatial resolutions of rainfall data. Hydrol. Earth Syst. Sci. 2019, 23, 2647-2663. [CrossRef]

15. Kapangaziwiri, E.; Hughes, D.; Wagener, T. Incorporating uncertainty in hydrological predictions for gauged and ungauged basins in southern Africa. Hydrol. Sci. J. 2012, 57, 1000-1019. [CrossRef]

16. He, B.; Huang, X.; Ma, M.; Chang, Q.; Tu, Y.; Li, Q.; Zhang, K.; Hong, Y. Analysis of flash flood disaster characteristics in China from 2011 to 2015. Nat. Hazards 2018, 90, 407-420. [CrossRef]

17. Worqlul, A.W.; Yen, H.; Collick, A.S.; Tilahun, S.A.; Langan, S.; Steenhuis, T.S. Evaluation of CFSR, TMPA 3B42 and ground-based rainfall data as input for hydrological models, in data-scarce regions: The upper Blue Nile Basin, Ethiopia. Catena 2017, 152, 242-251. [CrossRef]

18. Xin, Z.; Shi, K.; Wu, C.; Wang, L.; Ye, L. Applicability of Hydrological Models for Flash Flood Simulation in Small Catchments of Hilly Area in China. Open Geosci. 2019, 11, 1168-1181. [CrossRef]

19. Yu, D.; Xie, P.; Dong, X.; Hu, X.; Liu, J.; Li, Y.; Peng, T.; Ma, H.; Wang, K.; Xu, S. Improvement of the SWAT model for event-based flood simulation on a sub-daily timescale. Hydrol. Earth Syst. Sci. 2018, 22, 5001-5019. [CrossRef]

20. Brocca, L.; Moramarco, T.; Melone, F.; Wagner, W.; Hasenauer, S.; Hahn, S. Assimilation of Surface- and Root-Zone ASCAT Soil Moisture Products Into Rainfall-Runoff Modeling. IEEE Trans. Geosci. Remote Sens. 2012, 50, 2542-2555. [CrossRef]

21. Brocca, L.; Melone, F.; Moramarco, T. Distributed rainfall-runoff modelling for flood frequency estimation and flood forecasting. Hydrol. Process. 2011, 25, 2801-2813. [CrossRef]

22. Massari, C.; Brocca, L.; Barbetta, S.; Papathanasiou, C.; Mimikou, M.; Moramarco, T. Using globally available soil moisture indicators for flood modelling in Mediterranean catchments. Hydrol. Earth Syst. Sci. 2014, 18, 839-853. [CrossRef]

23. Massari, C.; Brocca, L.; Ciabatta, L.; Moramarco, T.; Gabellani, S.; Albergel, C.; De Rosnay, P.; Puca, S.; Wagner, W. The Use of H-SAF Soil Moisture Products for Operational Hydrology: Flood Modelling over Italy. Hydrology 2015, 2, 2-22. [CrossRef]

24. Massari, C.; Camici, S.; Ciabatta, L.; Brocca, L. Exploiting Satellite-Based Surface Soil Moisture for Flood Forecasting in the Mediterranean Area: State Update Versus Rainfall Correction. Remote Sens. 2018, 10, 292. [CrossRef]

25. Masseroni, D.; Cislaghi, A.; Camici, S.; Massari, C.; Brocca, L. A reliable rainfall-runoff model for flood forecasting: Review and application to a semi-urbanized watershed at high flood risk in Italy. Hydrol. Res. 2016, 48, 726-740. [CrossRef]

26. Liu, D.; Xu, Y.; Guo, S.; Liu, P.; Rheinheimer, D.E. A modified Green-Ampt model for water infiltration and preferential flow. Hydrol. Res. 2016, 47, 1172-1181. [CrossRef]

27. Beven, K. Down to Basics: Runoff Processes and the Modelling Process. In Rainfall-Runoff Modelling; Wiley: Hoboken, NJ, USA, 2012; pp. 1-23. [CrossRef]

28. Sun, R.; Hernández, F.; Liang, X.; Yuan, H. A Calibration Framework for High-Resolution Hydrological Models Using a Multiresolution and Heterogeneous Strategy. Water Resour. Res. 2020, 56, e2019WR026541. [CrossRef]

29. Foglia, L.; Hill, M.C.; Mehl, S.W.; Burlando, P. Sensitivity analysis, calibration, and testing of a distributed hydrological model using error-based weighting and one objective function. Water Resour. Res. 2009, 45. [CrossRef]

30. Fernández-Pato, J.; Caviedes-Voullième, D.; García-Navarro, P. Rainfall/runoff simulation with 2D full shallow water equations: Sensitivity analysis and calibration of infiltration parameters. J. Hydrol. 2016, 536, 496-513. [CrossRef]

31. Gan, Y.; Liang, X.-Z.; Duan, Q.; Ye, A.; Di, Z.; Hong, Y.; Li, J. A systematic assessment and reduction of parametric uncertainties for a distributed hydrological model. J. Hydrol. 2018, 564, 697-711. [CrossRef]

32. Beck, M.B. Water quality modeling: A review of the analysis of uncertainty. Water Resour. Res. 1987, 23, 1393-1442. [CrossRef]

33. Cheng, C.-T.; Zhao, M.-Y.; Chau, K.W.; Wu, X.-Y. Using genetic algorithm and TOPSIS for Xinanjiang model calibration with a single procedure. J. Hydrol. 2006, 316, 129-140. [CrossRef] 
34. Haan, C.T.; Barfield, B.J.; Hayes, J.C. 13-Hydrologic Modeling. In Design Hydrology and Sedimentology for Small Catchments; Haan, C.T., Barfield, B.J., Hayes, J.C., Eds.; Academic Press: San Diego, CA, USA, 1994; pp. 455-474.

35. Chen, F.; Dudhia, J. Coupling an Advanced Land Surface-Hydrology Model with the Penn State-NCAR MM5 Modeling System. Part I: Model Implementation and Sensitivity. Mon. Weather Rev. 2001, 129, 569-585. [CrossRef]

36. Doorenbos, J.; Pruitt, W. Appendix II-Background and development of methods to predict reference crop evapotranspiration (ETo). In Guidelines for Predicting Crop Water Requirements; FAO: Rome, Italy, 1977; pp. 108-119.

37. Famiglietti, J.S.; Wood, E.F. Multiscale modeling of spatially variable water and energy balance processes. Water Resour. Res. 1994, 30, 3061-3078. [CrossRef]

38. Brocca, L.; Melone, F.; Moramarco, T. On the estimation of antecedent wetness conditions in rainfall-runoff modelling. Hydrol. Process. Int. J. 2008, 22, 629-642. [CrossRef]

39. Corradini, C.; Melone, F.; Ubertini, L. A Semi-Distributed Model for Direct Runoff Estimate; IASTED ACTA Press: Anahheim, CA, USA, 1995; pp. 541-545.

40. Andreadis, K.M.; Clark, E.A.; Wood, A.W.; Hamlet, A.F.; Lettenmaier, D.P. Twentieth-Century Drought in the Conterminous United States. J. Hydrometeorol. 2005, 6, 985-1001. [CrossRef]

41. Corradini, C.; Morbidelli, R.; Saltalippi, C.; Melone, F. An adaptive model for flood forecasting on medium size basins. Appl. Simul. Model. 2002, 555-559.

42. Haan, C.T.; Barfield, B.J.; Hayes, J.C. 3-Rainfall-Runoff Estimation in Storm Water Computations. In Design Hydrology and Sedimentology for Small Catchments; Haan, C.T., Barfield, B.J., Hayes, J.C., Eds.; Academic Press: San Diego, CA, USA, 1994; pp. 37-103.

43. Chow, V.T.; Maidment, D.R.; Larry, W. Mays. Applied Hydrology, International ed.; MacGraw-Hill, Inc.: New York, NY, USA, 1988; p. 149.

44. Gan, T.Y.; Dlamini, E.M.; Biftu, G.F. Effects of model complexity and structure, data quality, and objective functions on hydrologic modeling. J. Hydrol. 1997, 192, 81-103. [CrossRef]

45. Klemeš, V. Operational testing of hydrological simulation models. Hydrol. Sci. J. 1986, 31, 13-24. [CrossRef]

46. Kling, H.; Fuchs, M.; Paulin, M. Runoff conditions in the upper Danube basin under an ensemble of climate change scenarios. J. Hydrol. 2012, 424, 264-277. [CrossRef]

47. Gupta, M. Model Calibration and Uncertainty Estimation. In Encyclopedia of Hydrological Sciences; Wiley: Hoboken, NJ, USA, 2005.

48. Matonse, A.H.; Kroll, C.N. Applying hillslope-storage models to improve low flow estimates with limited streamflow data at a watershed scale. J. Hydrol. 2013, 494, 20-31. [CrossRef]

49. Son, K.; Sivapalan, M. Improving model structure and reducing parameter uncertainty in conceptual water balance models through the use of auxiliary data. Water Resour. Res. 2007, 43. [CrossRef]

50. Muleta, M.K.; Nicklow, J.W. Sensitivity and uncertainty analysis coupled with automatic calibration for a distributed watershed model. J. Hydrol. 2005, 306, 127-145. [CrossRef]

51. Van Werkhoven, K.; Wagener, T.; Reed, P.; Tang, Y. Sensitivity-guided reduction of parametric dimensionality for multi-objective calibration of watershed models. Adv. Water Resour. 2009, 32, 1154-1169. [CrossRef]

52. Nossent, J.; Elsen, P.; Bauwens, W. Sobol' sensitivity analysis of a complex environmental model. Environ. Model. Softw. 2011, 26, 1515-1525. [CrossRef]

53. Mahapatra, S.; Jha, M.K.; Biswal, S.; Senapati, D. Assessing Variability of Infiltration Characteristics and Reliability of Infiltration Models in a Tropical Sub-humid Region of India. Sci. Rep. 2020, 10, 1515. [CrossRef] [PubMed]

54. Tügel, F.; Özgen-Xian, I.; Marafini, E.; Hadidi, A.; Hinkelmann, R. Flash flood simulations for an Egyptian city-mitigation measures and impact of infiltration. Urban Water J. 2020, 17, 396-406. [CrossRef]

55. Tian, J.; Liu, J.; Wang, Y.; Wang, W.; Li, C.; Hu, C. A coupled atmospheric-hydrologic modeling system with variable grid sizes for rainfall-runoff simulation in semi-humid and semi-arid watersheds: How does the coupling scale affects the results? Hydrol. Earth Syst. Sci. 2020, 24, 3933-3949. [CrossRef]

56. Mizukami, N.; Rakovec, O.; Newman, A.J.; Clark, M.P.; Wood, A.W.; Gupta, H.V.; Kumar, R. On the choice of calibration metrics for "high-flow" estimation using hydrologic models. Hydrol. Earth Syst. Sci. 2019, 23, 2601-2614. [CrossRef] 
57. Santos, L.; Thirel, G.; Perrin, C. Technical note: Pitfalls in using log-transformed flows within the KGE criterion. Hydrol. Earth Syst. Sci. 2018, 22, 4583-4591. [CrossRef]

58. Pool, S.; Vis, M.; Seibert, J. Evaluating model performance: Towards a non-parametric variant of the Kling-Gupta efficiency. Hydrol. Sci. J. 2018, 63, 1941-1953. [CrossRef]

59. López, P.L.; Sutanudjaja, E.H.; Schellekens, J.; Sterk, G.; Bierkens, M.F.P. Calibration of a large-scale hydrological model using satellite-based soil moisture and evapotranspiration products. Hydrol. Earth Syst. Sci. 2017, 21, 3125-3144. [CrossRef]

60. Gupta, H.V.; Kling, H.; Yilmaz, K.K.; Martinez, G.F. Decomposition of the mean squared error and NSE performance criteria: Implications for improving hydrological modelling. J. Hydrol. 2009, 377, 80-91. [CrossRef]

61. Mathevet, T.; Gupta, H.; Perrin, C.; Andréassian, V.; Le Moine, N. Assessing the performance and robustness of two conceptual rainfall-runoff models on a worldwide sample of watersheds. J. Hydrol. 2020, 585, 124698. [CrossRef]

62. Camici, S.; Massari, C.; Ciabatta, L.; Marchesini, I.; Brocca, L. Which rainfall score is more informative about the performance in river discharge simulation? A comprehensive assessment on 1318 basins over Europe. Hydrol. Earth Syst. Sci. 2020, 24, 4869-4885. [CrossRef]

63. Brocca, L.; Filippucci, P.; Hahn, S.; Ciabatta, L.; Massari, C.; Camici, S.; Schüller, L.; Bojkov, B.; Wagner, W. SM2RAIN-ASCAT (2007-2018): Global daily satellite rainfall data from ASCAT soil moisture observations. Earth Syst. Sci. Data 2019, 11, 1583-1601. [CrossRef]

64. Ly, S.; Charles, C.; Degre, A. Different methods for spatial interpolation of rainfall data for operational hydrology and hydrological modeling at watershed scale: A review. Biotechnol. Agron. Soc. Environ. 2013, 17, 392-406.

65. Mel, R.; Lionello, P. Storm Surge Ensemble Prediction for the City of Venice. Weather Forecast. 2014, 29, 1044-1057. [CrossRef]

66. Mel, R.; Lionello, P. Probabilistic Dressing of a Storm Surge Prediction in the Adriatic Sea. Adv. Meteorol. 2016, 2016, 3764519. [CrossRef]

67. House, P.; Lannoy, G.I.; Walker, J. Hydrologic Data Assimilation. In Approaches to Managing Disaster-Assessing Hazards, Emergencies and Disaster Impacts; IntechOpen: London, UK, 2012. [CrossRef]

Publisher's Note: MDPI stays neutral with regard to jurisdictional claims in published maps and institutional affiliations.

(C) 2020 by the authors. Licensee MDPI, Basel, Switzerland. This article is an open access article distributed under the terms and conditions of the Creative Commons Attribution (CC BY) license (http://creativecommons.org/licenses/by/4.0/). 